\title{
Mobility-Related Behavioral Flexibility and Routines
}

\author{
A Validation Study
}

\author{
Susanne Penger ${ }^{1}$ (D) and Kerstin Conrad ${ }^{2}$ \\ ${ }^{1}$ Interdisciplinary Ageing Research (IAW), Goethe University Frankfurt, Germany \\ ${ }^{2}$ ILS - Research Institute for Regional and Urban Development Dortmund, Germany
}

\begin{abstract}
Few empirical studies have explored psychological attitudes toward out-of-home mobility in old age. We aimed to validate an instrument to assess mobility-related behavioral flexibility and routines in the context of everyday mobility and successful aging. Data were gathered from face-to-face interviews and travel diaries of 211 community-dwelling older adults (aged 65-92) in Germany. Analysis revealed sufficient reliability and confirmed the factorial and convergent validity of the instrument. Mobility-related behavioral flexibility predicted the number of daily trips, particularly by mobility-impaired participants, and was strongly linked to autonomy and to psychological well-being. However, a preference for routines predicted neither out-of-home mobility nor further outcomes. The results demonstrate the importance of mobility-related flexibility in maintaining an active and independent life in old age.
\end{abstract}

Keywords: out-of-home mobility, mobility-related attitudes, aging in place, person-environment interaction, active aging

Staying mobile in old age is a key determinant of health, social participation, and quality of life (e.g., Nordbakke \& Schwanen, 2014). From an environmental gerontology perspective, mobility always occurs in a specific sociospatial environmental context and constitutes one successful behavioral outcome in the dynamic exchange process between an individual and their living environment (Altman, 1975; Carp, 1988; Chaudhury \& Oswald, 2019). According to the well-known ecological theory of aging (ETA; Lawton \& Nahemow, 1973), adaptive behavior in old age depends on both the individual's level of competence and environmental demands, whereby a good person-environment fit is achieved when both entities are balanced, resulting in a variety of aging-related outcomes, such as well-being and independence (Wahl et al., 2012). In terms of outdoor mobility in older adults, a major contribution was made by Slaug and colleagues (2019) in capturing person-environment fit on an objective level, based on the well-established concept of accessibility (Iwarsson \& Ståhl, 2003). In contrast, the present study examines how older individuals evaluate their ability to deal psychologically with mobility-related challenges. In other words, we focus on the assessment of subjective beliefs for coping with mobility-related challenges as well as mobility-related habitual preferences when outside the home. We refer to a standardized measurement tool, proposed by Penger and Oswald (2017), that assesses mobility-related behavioral flexibility and preferences for routines (MBFR) in old age. Until now, investigations into the newly developed MBFR questionnaire has only been exploratory. Thus, the present study serves to further evaluate its psychometric properties in the context of everyday mobility and successful aging.

\section{Psychological Contributions to Outdoor Mobility}

As Webber et al. (2010) highlighted, psychosocial factors are fundamental in determining mobility in later life but have not yet been sufficiently investigated in a differentiated and comprehensive manner (Goins et al., 2015). There have been many attempts to examine the role of efficacy beliefs (Bandura, 1978) in enhancing physical activity among older adults. Findings consistently showed that task-specific efficacy beliefs are substantially associated with improved activity (e.g., physical exercise) in later life (e.g., Feltz \& Payment, 2005; Gellert et al., 2015; McAuley et al., 2006; Perkins et al., 2008; Sniehotta et al., 2013). Efficacy beliefs are also associated with fear of falling and fear of moving outdoors (Iwarsson et al., 2013; Rantakokko et al., 2009), indicating that confidence in the ability to perform everyday tasks without falling reduces the risk of subsequent falls (Cumming et al., 2000) and substantially predicts physical functioning in 
older adults (Tinetti et al., 1994). Furthermore, evidence suggests that, besides perceived self-efficacy, high affective outcome expectancy enhances the frequency and duration of physical exercise in old age (Gellert et al., 2012). However, many studies neglect everyday outdoor mobility, such as regularly walking to the supermarket or using different means of transport to pursue leisure activities. As an exception, the European project MOBILATE (Mollenkopf et al., 2005) showed that psychological resources - and especially control beliefs, coping strategies, outdoor place attachment, and outdoor motivation - were associated with several mobility outcomes (Oswald et al., 2005). Adaptive coping strategies have also been studied concerning mobility (e.g., distance of travel) and proved to enhance mobility and active participation in outdoor activities (Siltanen et al., 2019; Skantz et al., 2020).

Over the past decades, efforts have been made to better understand the importance of attitudes in influencing mobility behavior. By referring mainly to the socialpsychological theory of planned behavior (Ajzen, 1991), the one-dimensional view that transport behavior is predominantly affected by spatial environmental characteristics has been extended to include intrapersonal factors, such as subjective values and needs (Busch-Geertsema et al., 2016). Although Haustein (2012) applied an attitude-based segmentation approach to capture the heterogeneity of travel patterns among older adults in Germany, mobility-related attitudes have scarcely been explored concerning old and very old age.

To overcome the assumption that mobility behavior is a process of rational choices, the concept of mobility-related habits was introduced into existing theories (Bamberg et al., 2003). Thus, the habitual phenomenon of daily travel behavior affects behavior in old age (Busch-Geertsema et al., 2016). Outdoor mobility routines based primarily on past behavior are expected to reduce complexity when being out and about in familiar contexts (Wood et al., 2005). In community-dwelling older adults, the role of routinization is either considered to be an adaptive strategy or a risk factor for vulnerability in old age (Reich \& Zautra, 1991; Zisberg et al., 2009), linked to anxiety, depression, cognitive impairment, and limited instrumental activities of daily living (Bergua et al., 2006, 2013; Bouisson, 2002). Overall, the theoretical and empirical evidence on the meaning of routines and habits in later life is conflicting.

\section{Mobility-Related Behavioral Flexibility and Routines (MBFR)}

The findings presented emphasize the need to integrate conceptual and empirical reflections from both environmental gerontology and transport research. Furthermore, appropriate and valid measures are required that capture domain-specific, mobility-related attitudes relevant to everyday life among older adults by taking into account both goal-oriented and habitual aspects of outdoor mobility. To address this need, Penger and Oswald (2017) introduced a new concept to describe behavioral flexibility and preferences for routines (MBFR) in everyday situations involving older out-of-home adults; they proposed a standardized measurement tool to operationalize these attitudinal constructs. Taken from the well-established tripartite attitude model (e.g., Rosenberg \& Hovland, 1960), MBFR is considered to reflect all three components of an attitude by assessing beliefs (cognitive), preferences (affective) as well as behavioral tendencies (behavioral) concerning one's own daily outdoor mobility behavior.

Following previous reflections on flexibility (e.g., Bitterwolf, 1992; Brandes, 1980), mobility-related behavioral flexibility was theoretically conceptualized as the belief that one's own mobility behavior can be adapted according to the perceived challenges of out-of-home mobility (Penger \& Oswald, 2017). Empirical findings from gerontological mobility research (cf. Gellert et al., 2015; Phillips et al., 2013) suggest that these challenges may be related either to age-related changes within the person (e.g., functional limitations, impairments of cognitive or psychomotor capacity) or to the environment (e.g., unfamiliar outdoor surroundings, poor connectivity, or complex traffic conditions). In operationalizing mobility-related behavioral flexibility, the MBFR instrument (Penger \& Oswald, 2017) therefore aimed to capture two distinguishable dimensions: on the one hand, the belief in the ability to cope with personal challenges in everyday outdoor mobility (BFP) and, on the other hand, the belief in being able to flexibly adapt to environmental barriers (BFE). Since these flexibility dimensions address mobility-related attitudes toward possible subsequent mobility behavior, they are assumed to capture goal-directed behavioral tendencies representing person-environment processes of agency in later life (Chaudhury \& Oswald, 2019; Oswald \& Wahl, 2019; Wahl et al., 2012). Thus, behavioral flexibility may be associated with other general as well as domainspecific proactive adaptation processes, such as perceived competence, control, and efficacy beliefs (Skinner, 1996).

As daily activity and mobility behavior are often characterized by repetition and routines that tend to increase with age, the MBFR instrument involved a separate factor mapping preferences for mobility-related routines and habits (ROU). An affinity for routines may manifest itself in a dislike of changes to daily routines or the order in which tasks are performed. Because of its tenacious nature, ROU may be linked more to assimilative adaptation strategies related to goal pursuit (Brandtstädter \& Renner, 1990) than to flexible goal adjustment. At the same time, 
adherence to mobility-related routines may result from an older individual's mobility biography (Müggenburg et al., 2015), such that being outside the home may evoke or strengthen both a sense of security and control as well as connectedness and stability (Iwarsson et al., 2013; Scheiner, 2006). These cognitive and affective environmental bonds represent person-environment processes of belonging (Chaudhury \& Oswald, 2019; Oswald \& Wahl, 2019). In summary, with its factors BFE, BFP, and ROU, the standardized MBFR instrument depicts attitudinal aspects of everyday out-of-home mobility in old age (Penger \& Oswald, 2017).

Referring to the ETA (Lawton, 1982), the maintenance of daily out-of-home mobility is more difficult in older adults with low personal competence levels (e.g., poor functional capacity), resulting in greater dependence on environmental conditions and reduced accessibility to meaningful places outside the home (Rantanen, 2013; Slaug et al., 2019). Psychological resources such as mobility-related attitudes may therefore play a crucial role in helping older individuals, especially those with reduced competencies, to (re)gain a good fit with their living environment. We therefore assume that beliefs in the ability to cope with mobility-related challenges when out and about, represented by the flexibility dimensions, extend the area of adaptive behavioral outcomes and positive affect and thereby improve ways to stay mobile, especially in mobility-impaired individuals (Engeln, 2003). In contrast, a tendency to stick to mobility-related routines may reduce the ability to deal with challenging environmental conditions. However, as already outlined, the role of preferences for mobility-related routines and habits (ROU) in hindering or fostering outdoor mobility has not been fully clarified and will be empirically examined in the present study.

\section{The Present Study}

The current study further validates the MBFR questionnaire by investigating aspects of factorial, construct, and criterion validity among community-dwelling older adults in an urban setting in Germany. Specifically, we examined MBFR in later life and how it is associated with related attitudinal variables, actual out-of-home mobility behavior, and further outcomes of successful aging. Our study is therefore the first to use cross-sectional data to conduct a comprehensive empirical investigation of these associations on a latent level.

The study was guided by a conceptual framework (Conrad et al., 2018; Penger et al., 2018) derived from the MBIS project which will be introduced in the method section. The present work was based on the following theoretical assumptions: (1) The MBFR instrument was expected to show sufficient factorial validity and reliability. More precisely, we expected being able to empirically confirm the three-factorial structure of the MBFR instrument which resulted from explorative analyses by Penger and Oswald (2017). (2) As an indication of sufficient convergent validity, the MBFR dimensions were presumed to be linked to general coping styles and mobility-specific attitudes commonly used in the context of active and successful aging, which reflect motivation or perceived competencies related to outdoor mobility (Haustein, 2012; Oswald et al., 2005). More precisely, BFE and BFP were expected to be associated with a lower level of regressive coping and a higher degree of outdoor motivation, walking attitude, and public transport control (These concepts are explained in detail in the section on measures). Because of contradictory findings of previous research regarding the meaning of routinization in old age, directions of relationships between ROU and the respective variables need to be clarified in the present study. (3) As an indication of adequate concurrent validity, we considered several structural relations between the three MBFR dimensions, on the one hand, and actual out-of-home mobility behavior, perceived everyday autonomy, and subjective psychological well-being, on the other hand. MBFR was assumed to predict the number of daily trips (3.1) as well as autonomy (3.2) and well-being (3.3), thus reflecting outcomes of successful aging. (4) Finally, links between MBFR and the number of daily trips were assumed to be stronger in the mobility-impaired subgroup of older participants.

\section{Method}

\section{Procedure and Study Sample}

Data were gathered as part of the project "Staying Mobile in Stuttgart" (MBIS), conducted by the interdisciplinary research group "Age-Friendly City - Autonomy and Sustainable Mobility in the Context of Climate Change" (autonomMOBIL; Conrad et al., 2018). Inclusion criteria for the MBIS study were (1) community-dwelling, (2) 65 years of age or older, (3) living in one of two selected urban areas in Stuttgart, Germany (one district in the inner city, one district on the periphery), and (4) able to pass the Mini-Mental State Examination (MMSE; Folstein et al., 1975). The gross sample was drawn from the official public register in Stuttgart, Germany. Individuals were contacted in writing, and study objectives and procedures were explained to them. Standardized comprehensive face-toface interviews lasting an average of 90 minutes were conducted at the place of residence of the consenting participants. All participants gave written informed consent. After the interview, the participants filled out an 
Table 1. Basic characteristics of the study sample $(N=211)$

\begin{tabular}{|c|c|c|}
\hline Background variables & N & $M \pm S D$ (range) or \% \\
\hline Age, years & 211 & $74.6 \pm 6.0(65-92)$ \\
\hline Female & 120 & $56.9 \%$ \\
\hline \multicolumn{3}{|l|}{ Education (selected categories) } \\
\hline Elementary school & 15 & $7.1 \%$ \\
\hline University & 84 & $40.0 \%$ \\
\hline \multicolumn{3}{|l|}{ Occupation } \\
\hline Retired & 200 & $94.8 \%$ \\
\hline \multicolumn{3}{|c|}{ Net income per person ${ }^{a}$ (combined categories) } \\
\hline Up to $€ 1000$ per month & 13 & $7.3 \%$ \\
\hline$€ 1000-2000$ per month & 92 & $51.7 \%$ \\
\hline$€ 2000-3000$ per month & 44 & $24.7 \%$ \\
\hline Over $€ 3000$ per month & 29 & $16.3 \%$ \\
\hline Refused to answer & 33 & $15.6 \%$ \\
\hline \multicolumn{3}{|l|}{ Household composition } \\
\hline Living alone & 89 & $42.2 \%$ \\
\hline \multicolumn{3}{|l|}{ Residential area } \\
\hline Inner city & 87 & $41.4 \%$ \\
\hline \multicolumn{3}{|l|}{ Duration of residence } \\
\hline In the current district, years & 209 & $39.4 \pm 18.5(1-89)$ \\
\hline Driver's license & 192 & $91.0 \%$ \\
\hline \multicolumn{3}{|l|}{ Car ownership per household } \\
\hline None & 64 & $30.3 \%$ \\
\hline \multicolumn{3}{|c|}{ Functional limitations (selected categories) } \\
\hline None & 148 & $70.5 \%$ \\
\hline Impaired walking & 46 & $21.9 \%$ \\
\hline \multicolumn{3}{|l|}{ Mobility behavior ${ }^{b}$} \\
\hline Number of trips per day & 181 & $3.0 \pm 1.3(0.4-7.1)$ \\
\hline
\end{tabular}

Note. $N=$ Absolute frequency of participants in the respective category. ${ }^{a}$ Net income per person was calculated using the OECD equivalent Scale $(O E C D$, 2019), which divides net household income by a factor based on the number and age of the household members in order to take into account that household needs are not directly proportional to the number of members. ${ }^{b}$ Mobility behavior was measured using a travel diary. The number of trips per day was calculated by averaging the total number of trips per person over seven consecutive days.

additional, brief questionnaire and recorded their mobility behavior in a 7-day travel diary. All data were collected in strictly pseudonymous form.

A total of 211 community-dwelling older adults aged $65-92$ years $(M=74.6$ years old; $S D=6.0)$ participated in the study ( $56.9 \%$ female). Table 1 lists the basic characteristics. Almost all participants were no longer in the workforce. Nearly half the participants lived in the inner city (41.1\%), and around half lived alone. The sample was characterized by a relatively high socioeconomic status: A substantial proportion of the sample had an academic background (40.0\%) and a fairly high monthly net income ( $41 \%$ received at least $€ 2000$ per month). Participants were very familiar with their residential area, having lived there for a mean of roughly 40 years $(S D=18.5)$. Mobility-related functional capacity was high, and less than one-quarter of respondents were impaired in walking. The background variables presented in the samples were very similar in both districts.
Although nearly all participants held a driver's license, about one-third of the households did not own a car. The sample was fairly mobile concerning activities outside the home. A total of 3,853 out-of-home trips were captured in the travel diaries of 181 participants. Based on German mobility surveys, the average number of trips per person per day $(M=3.0 ; S D=1.3)$ was somewhat above average (BMVI, 2018; KIT, 2016).

\section{Measures}

\section{Mobility-Related Behavioral Flexibility and Routines (MBFR)}

Initially, the MBFR instrument was developed and empirically tested in a preliminary pilot study (Penger \& Oswald, 2017). The self-report questionnaire consists of three factors: behavioral flexibility concerning environmental challenges (BFE), which reflects the ability to cope with mobility-related environmental barriers (e.g., relocated 
bus stop, traffic); behavioral flexibility concerning personal challenges (BFP), which captures age-related declines (e.g., functional limitations, walking difficulties) in the context of out-of-home mobility; lastly, preference for routines (ROU), which reflects mobility-related habits (e.g., sticking to the same places or routes out-of-home). Respondents were invited to indicate the extent to which they agree with each statement on a 5-point Likert scale ranging from strongly disagree (1) to strongly agree (5). The response format scale was considered to be continuous.

After the first pilot test, we modified the initial MBFR instrument (Penger \& Oswald, 2017) in a process that was closely accompanied by recommendations from gerontology experts aimed at increasing the content-related quality of the instrument. To ensure that the instrument was parsimonious, the final questionnaire consisted of 15 items, with each factor represented by 5 items.

\section{Attitudinal Variables}

Regressive coping style was measured using the Coping Pattern Schedule (CPS; Staudinger et al., 1998), which reflects the tendency to give up or hand over responsibility to someone else when faced with difficult situations. Motivation-oriented attitudes toward the outdoor home environment were measured using the concept of outdoor motivation, which reflects a preference for being outside rather than inside the home (Oswald et al., 2005). Attitudes toward choice of travel mode comprise functional and symbolic-affective evaluations of various transport modes (Haustein, 2012). We applied the attitudinal domains of public transport control to cover perceived ability to use public transportation, and walking attitude to capture general walking enjoyment and health-related motivation to walk.

\section{Everyday Autonomy (AUT)}

Self-rated physical functioning in daily life was measured using five indicators. The functional component of the short form of the Late-Life Function and Disability Instrument (SF-LLFDI; Haley et al., 2002) covers functional limitations at an early stage of decline. The degree of impairment in performing everyday tasks within the last 6 months as well as perceived independence in daily living (Oswald et al., 2002) were assessed using a single item. Finally, we assessed physical and mental health status using the SF-12 questionnaire (SF-12v2; Ware et al., 1996) and a single item on perceived general health. Based on the current sample, the internal consistency of the latent factor AUT was high $(\omega=.87)$.

\section{Psychological Well-Being (WELL)}

The assessment of psychological well-being in old age adopted a rather hedonic approach and was based on five scales measuring cognitive and affective aspects of subjective quality of life. Positive affect was measured using the Positive and Negative Affect Schedule (PANAS; Watson et al., 1988). Mood disturbance and motivation disturbance was rated using the Geriatric Depression Scale (GDS; Yesavage et al., 1983). We used the Satisfaction with Life Scale (SWLS; Diener et al., 1985) to cover cognitive aspects of subjective well-being and the Positive Valuation of Life Scale (P-VOL; Lawton et al., 2001) to address positive attachment to life. In the current sample, the internal consistency of the latent factor WELL was acceptable $(\omega=.69)$.

\section{Number of Daily Trips (TRIPS)}

Similar to German national mobility surveys (BMVI, 2018; KIT, 2016), we measured outdoor mobility behavior using self-reported travel diaries completed at the end of each day for a total of 7 consecutive days. From these, we extracted the number of daily trips per person, a commonly used variable in mobility research. One trip was defined as any out-of-home route for any particular purpose or destination, independent of the duration and which or how many modes of transport were used. Return trips also counted as trips.

\section{Data Analysis}

\section{Strategy of Analysis}

Confirmatory factor analyses (CFA) were used to test factorial validity, and bivariate Pearson correlations were conducted to examine convergent validity. To investigate concurrent validity, we tested hypothesized structural associations using structural equation modeling (SEM). Because of the small sample size in a subsample of the study, we used multiple regression analysis at a manifest level to examine partial structures. We conducted all analyses using the Mplus program, Version 8 (Muthén \& Muthén, 1998). Because of divergence from normal distribution in most observed variables, we applied the full information maximum likelihood robust method (MLR) as an estimator for CFAs, SEM, and regression analysis. The data contained few missing values (a maximum of $9 \%$ missing data in at least one of the variables used in the face-to-face interviews and $14.2 \%$ in the travel diaries). We considered missing values to be missing at random and used the MLR estimator of the Mplus program to simultaneously replace all of them when model parameters were estimated.

\section{Model Fit Evaluation and Reliability}

To evaluate the model fit of CFAs and SEM in our study, we included several goodness-of-fit indices in the Mplus program: the likelihood-ratio $\chi^{2}$-test and its associated $p$-value, the root mean square error of approximation (RMSEA), the comparative fit index (CFI), and the 
Table 2. Model fit indices of the MBFR instrument in different confirmatory factor analyses

\begin{tabular}{lcccccccc}
\hline & $\chi^{2}$ & $d f$ & $\chi^{2} / d f$ & $\Delta S B-\chi^{2}$ & $\Delta d f$ & RMSEA & CFI & SRMR \\
\hline Model 1 & 148.48 & 87 & 1.71 & 23.56 & 1 & .058 & .930 & .056 \\
Model 2 & 124.59 & 86 & 1.45 & & & .046 & .956 & .054 \\
Model 3 & 175.69 & 88 & 2.00 & 34.55 & 2 & .069 & .900 & .061 \\
\hline
\end{tabular}

Note. $N=211$. Model 1 = correlated three-factor model; Model 2 = correlated three-factor model with freely estimated error covariance between items 21 and 25 within factor ROU; Model 3 = correlated two-factor model with all 10 BFE and BFP items loading on one factor and ROU as a separate factor. $\Delta \mathrm{SB}-\chi^{2}=$ Satorra-Bentler scaled $\chi^{2}$ difference when compared to the least restrictive Model 2.

standardized root mean square residual (SRMR). Following established recommendations (Hu \& Bentler, 1999; McDonald \& Ho, 2002; Schermelleh-Engel et al., 2003), good (acceptable) model fit was indicated by $\chi^{2} / d f<$ $2(<3)$, RMSEA $\leq .06(\leq .08)$, CFI $\geq .95(\geq .90)$, and SRMR $\leq .08(\leq .10)$. We evaluated internal consistency reliability using McDonald's omega (1999) and Bollen's omega coefficient (1980), as these are based on the factorial analysis framework and provide an appropriate alternative to the commonly used Cronbach's $\alpha$ for data that do not meet the assumption of $\tau$-equivalence in the test items (cf. Dunn et al., 2014). Satorra-Bentler (SB)-scaled $\chi^{2}$ difference tests were performed for nested model comparisons (Satorra \& Bentler, 2001).

\section{Results}

\section{Examination of Factorial Validity}

Our first goal was to evaluate the three-factorial structure of the revised MBFR instrument consisting of 15 items. Confirmatory factor analysis revealed an acceptable model fit (see model 1 in Table 2). The examination of modification indices revealed notable error covariance between items 21 ("Routines are important to me when I am out and about.") and 25 ("Routines are important to me when running my daily errands.") in the ROU factor. Because of the linguistic similarity, these two items should logically be correlated. We therefore conducted another CFA by freely estimating this error covariance, which demonstrated a very good fit to the data (see model 2 in Table 2). Satorra-Bentler-scaled $\chi^{2}$ difference test revealed significant improvement of model fit $\left(\Delta \mathrm{SB}-\chi^{2}=23.56, \Delta d f=1\right.$, $p<.001)$.

Table 3 shows that the internal consistency reliability of all three constructs was high. All factor loadings were greater than .40 and statistically significant $(p<.001)$. Study participants evaluated themselves as rather flexible when dealing with personal and especially environmental mobility-related challenges. All BFE and BFP mean item scores were above 3 , indicating positive affirmation (response scale 1-5). Correspondingly, most ROU items showed mean scores below 3. Ceiling and floor effects corresponded with sample characteristics, indicating fairly healthy and active respondents. Regarding associations between the three MBFR factors, the analyses showed a high correlation between the dimensions BFE and BFP $(r=.73 ; p<.001)$. Correlations with ROU turned out to be slightly lower, with moderate negative correlations between BFE and ROU $(r=-.33 ; p=.001)$, and BFP and $\operatorname{ROU}(r=-.23 ; p=.014)$.

The high correlation between BFE and BFP may indicate that the respective items load on a common factor. For this reason, we conducted another $\mathrm{CFA}$ in which all items associated with BFE and BFP now loaded only on one factor (model 3). The fit of this model was substantially decreased (see Table 2). Comparing model 2 against model 3, the Satorra-Bentler-scaled $\chi^{2}$ difference test indicated that the three-factorial solution described the data significantly better than the two-factor model $\left(\Delta \mathrm{SB}-\chi^{2}=34.55, \Delta d f=2\right.$, $p<.001)$. In the following, we therefore remain with the three-factor solution (model 2).

\section{Examination of Convergent Validity}

To gain insight into the convergent validity of the MBFR questionnaire, we estimated bivariate associations of the MBFR scales with concepts we expected to be related to mobility-related behavioral flexibility and routines in later life, i.e., general coping styles and mobility-related motivation and attitudes toward choice of travel mode (see Table 4).

Almost all correlations between the selected constructs and the MBFR dimensions proved to be significant. Regressive coping (RC) was negatively associated with both BFE and BFP, and positively linked to ROU. Furthermore, ROU demonstrated a moderate negative correlation with outdoor motivation $(\mathrm{OM})$ as well as a small but significant negative link with public transport control (PTC). A negative association with walking attitude (WA) was only marginal and not statistically significant $(r=-.12 ; p=$ .084). In contrast, BFE and BFP were positively related to all three mobility-related constructs (OM, PTC, WA). BFP showed a slightly stronger association with $\mathrm{OM}$, and BFE showed a stronger association with PTC. The strongest 
Table 3. MBFR factors and numbers, item content, mean (M), standard deviation (SD), standardized factor loading ( $\lambda$ ), and internal consistency ( $\omega$ ) from the confirmatory factor analysis (Model 2) of the 15-Item MBFR scales ( $N=211$ )

\begin{tabular}{|c|c|c|c|c|c|c|}
\hline Factor & No. & Item content & M & SD & $\lambda$ & $\omega$ \\
\hline \multirow[t]{6}{*}{ BFE } & & & & & & .79 \\
\hline & 1 & Even when hindrances occur on the way, I can generally still get to places that are of interest to me. & 4.15 & 0.77 & .81 & \\
\hline & 2 & Even when there is a lot of traffic on the way, I am still able to cope perfectly well. & 4.03 & 0.81 & .62 & \\
\hline & 8 & When I am interested in something, I am happy to visit new places as well. & 4.23 & 0.73 & .67 & \\
\hline & 9 & I can use different modes of transport (e.g., walking, car, bicycle, bus, train) flexibly. & 4.37 & 0.73 & .69 & \\
\hline & 24 & Hindrances on my way (e.g., relocated busstop or closed roads) don't pose a problem for me. & 3.88 & 1.17 & .57 & \\
\hline \multirow[t]{6}{*}{ BFP } & & & & & & .81 \\
\hline & 4 & Even when I'm not in especially good form, I am generally still able to be out and about. & 3.77 & 0.94 & .77 & \\
\hline & 12 & Not feeling well doesn't stop me from going shopping or pursuing other activities. & 3.63 & 0.94 & .65 & \\
\hline & 17 & Even when I have trouble walking, I can still pursue my outdoor activities. & 3.83 & 0.85 & .67 & \\
\hline & 22 & Even when I am a little unwell, I still go out. & 3.63 & 0.98 & .75 & \\
\hline & 28 & Even when I find it difficult to be out and about, I still know how to run my errands. & 4.03 & 0.74 & .46 & \\
\hline \multirow[t]{6}{*}{ ROU } & & & & & & .79 \\
\hline & 11 & I stick to routes I have always taken. & 3.42 & 1.12 & .68 & \\
\hline & 13 & I always want to be able to run my daily errands in the same places. & 2.62 & 1.19 & .68 & \\
\hline & 21 & Routines are important to me when I am out and about. & 2.67 & 1.11 & .60 & \\
\hline & 25 & Routines are important to me when running my daily errands. & 2.83 & 1.08 & .52 & \\
\hline & 29 & No matter what, I always prefer to take the same route. & 2.57 & 1.18 & .88 & \\
\hline
\end{tabular}

Note. Items are sorted according to the scale they belong to. No. = order of appearance in the final questionnaire. Theoretical response scales ranged from strongly disagree (1) to strongly agree (5); BFE = behavioral flexibility concerning environmental challenges; BFP = behavioral flexibility concerning personal challenges; ROU = preference for routines and habits; $\lambda$ = standardized factor loadings of confirmatory factor analysis; $\omega=$ McDonald's omega/Bollen's omega. Error covariance between items 21 and 25 within factor ROU was set free. All factor loadings were highly significant $(p<.001)$.

Table 4. Bivariate Pearson correlations between MBFR factor scores and related constructs

\begin{tabular}{lrrr}
\hline & BFE & BFP & ROU \\
\hline Regressive coping (RC) & -.29 & -.32 & .22 \\
Outdoor motivation (OM) & .24 & .31 & -.30 \\
Public transport control (PTC) & .41 & .35 & -.15 \\
Walking attitude (WA) & .45 & .43 & -.12 \\
\hline
\end{tabular}

Note. $N=193-211$. BFE = behavioral flexibility concerning environmental challenges; BFP = behavioral flexibility concerning personal challenges; $\mathrm{ROU}=$ preference for routines and habits. Significant correlations at the .05 level are indicated in bold font.

correlations were between walking attitude (WA) and both BFE and BFP.

\section{Examination of Concurrent Validity}

We performed structural equation modeling to examine the questionnaire's psychometric quality concerning concurrent validity. In accordance with existing studies on outof-home mobility, especially in later life, sex $(0=$ female; $1=$ male) and age were used as further predicting variables (e.g., Oswald et al., 2005). Other potential covariates such as residential area, academic background, net income, driver's license, or household composition did not show substantial associations with mobility-related outcomes in the present study and therefore were not taken into account within the structural equation model.

Table 5 displays the bivariate correlations between the variables used in the SEM. Most variables were significantly correlated with each other and therefore formed the basis for the following structural equation model. As already shown above, BFE and BFP were highly intercorrelated. To avoid collinearity that might lead to unreliable estimations, we included a second-order factor FLEX consisting of BFE and BFP as first-order factors. This approach agreed with the theoretical conceptualization of $\mathrm{BFE}$ and BFP, both reflecting dimensions of the overarching behavior flexibility construct. To ensure the identification of the higher-order factor model, we fixed the factor loadings from the first-order factors BFE and BFP to be equal.

Analyses of SEM revealed an appropriate model fit $\left[\chi^{2}=492.81(d f=333, p<.001), \chi^{2} / d f=1.48\right.$, RMSEA $=$ .048 , and SRMR $=.059, \mathrm{CFI}=.918]$. Because all factor loadings of observed variables were greater than .40 and statistically significant $(p<.001)$, we assumed the selected observed variables to be representative for the respective latent constructs.

Figure 1 shows the structural associations and coefficients for the constructs. To simplify the presentation, the measurement model of the SEM is not displayed. 
Table 5. Correlations between study variables used in the structural equation model

\begin{tabular}{|c|c|c|c|c|c|c|c|c|}
\hline & (1) & (2) & (3) & (4) & (5) & (6) & (7) & (8) \\
\hline (1) BFE & 1 & & & & & & & \\
\hline (2) BFP & .73 & 1 & & & & & & \\
\hline (3) ROU & -.33 & -.23 & 1 & & & & & \\
\hline (4) Sex & .04 & .05 & .09 & 1 & & & & \\
\hline (5) Age & -.26 & -.30 & .41 & .00 & 1 & & & \\
\hline (6) Trips & .25 & .28 & -.16 & .17 & -.39 & 1 & & \\
\hline (7) AUT & .64 & .54 & -.22 & .21 & -.38 & .40 & 1 & \\
\hline (8) WELL & .56 & .51 & -.28 & .09 & -.29 & .29 & .72 & 1 \\
\hline
\end{tabular}

Note. $N=211 . \mathrm{BFE}=$ behavioral flexibility concerning environmental challenges; BFP = behavioral flexibility concerning personal challenges; ROU = preference for routines and habits; sex $=0$ for female, 1 for male; trips = number of daily trips; AUT = autonomy; WELL = psychological well-being. Error covariance between items 21 and 25 of the factor ROU was set free. Significant correlations at the .05 level are indicated in bold font. Latent factors are displayed in CAPITAL letters.

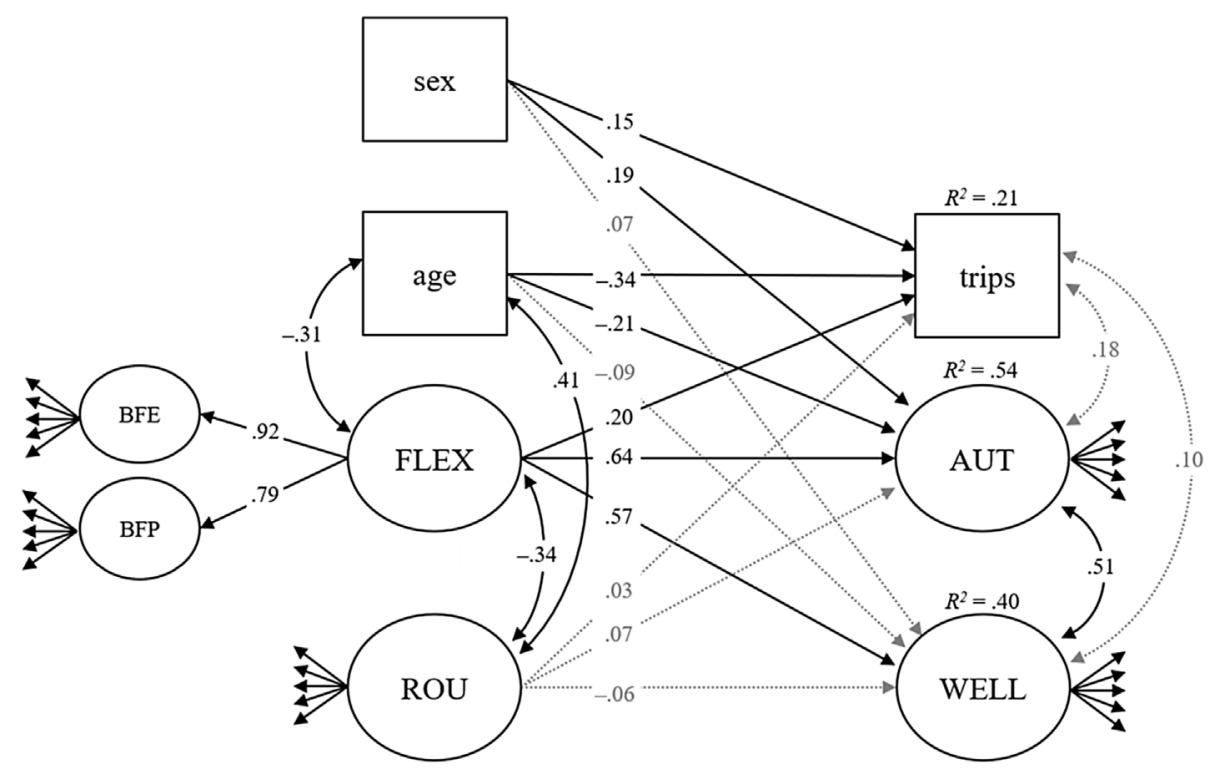

Figure 1. Structural section of the hypothesized structural equation model of sex, age, FLEX, and ROU predicting the number of daily trips, autonomy, and well-being $(N=211)$. For the sake of clarity, indicators of latent constructs are not displayed. Latent factors are presented in ellipses, observed variables in squares. Standardized estimates for significant paths at $p<.05$ are also presented. Nonsignificant paths are shown as dotted gray lines. Sex $=0$ for female, 1 for male; FLEX = mobility-related behavioral flexibility, second-order factor consisting of behavioral flexibility concerning environmental challenges (BFE), and concerning personal challenges (BFP); to ensure the identification of the higher-order factor model, factor loadings from first-order factors BFE and BFP were fixed to be equal; ROU = preference for routines and habits; trips = number of daily trips; AUT = everyday autonomy; WELL = psychological well-being. Model fit indices: $\chi^{2}=492.81(d f=333, p<.001), \chi^{2} / d f=1.48$; RMSEA $=.048 ; \mathrm{CFI}=.918 ;$ SRMR $=.059$.

Regarding correlations between predicting variables, older participants reported a stronger preference for routines (ROU; $r=.41 ; p<.001$ ), and FLEX was higher in younger participants $(r=-.31 ; p<.001)$. FLEX and ROU, in turn, were moderately negatively linked with each other $(r=-.34 ; p=.001)$.

With respect to out-of-home mobility, the analyses revealed that FLEX significantly predicted the number of daily trips $(\beta=.20 ; p=.020)$. The positive coefficient indicates that older adults with high FLEX values reported more daily trips. Both age $(\beta=-.34 ; p<.001)$ and sex $(\beta=.15 ; p=.025)$ were significantly linked to actual mobility behavior. ROU had no significant or meaningful effect on TRIPS, with a value close to 0 .

With respect to outcomes of successful aging, age negatively predicted an individual's everyday autonomy (AUT), $\beta=-.21 ; p=.003$. Furthermore, the reported levels of AUT were higher in men than in women $(\beta=.19 ; p=.003)$. 
However, FLEX proved to be the strongest predictor of AUT ( $\beta=.64 ; p<.001)$, whereas ROU had no relevant impact on AUT.

For psychological well-being (WELL), only FLEX showed a strong and positive predictive effect on WELL ( $\beta=.57$; $p<.001)$, whereas neither sex nor age nor ROU contributed to variance explanation in WELL.

Residuals of AUT and WELL showed a substantial correlation $(r=.51 ; p=.005)$, which cannot be explained by the predictors of the model. In contrast, TRIPS didn't show significant residual correlations with both AUT and WELL.

\section{Regression Analysis in Subsample}

To verify the greater relevance of the MBFR dimensions for daily outdoor activities of older individuals with reduced physical competencies, we set up a subgroup of the study sample, consisting of 62 participants limited in walking, hearing, or vision as the basis for regression analysis using the standardized factor scores of FLEX and ROU. Indeed, mobility-impaired older adults with greater levels of mobility-related flexibility showed significantly more out-of-home activity ( $\beta=.30 ; p=.011)$. The effect was nearly twice as high as in the total study sample. A preference for routines was again not linked to the number of daily trips (see Figure 2). Furthermore, sex no longer contributed to the prediction of TRIPS $(\beta=.06 ; p=.660$ ), while age did $(\beta=-.38 ; p=.009)$. FLEX and ROU were no longer significantly correlated $(r=-.11 ; p=.484)$.

\section{Discussion}

Our study investigated different validity aspects of the revised and shortened 15-item MBFR instrument for measuring mobility-related behavioral flexibility and routines in the context of everyday mobility and outcomes of successful aging. As anticipated, the findings revealed good internal consistency and factorial validity of the three-factor model, confirming the questionnaire's ability to differentiate between the three theoretical MBFR dimensions BFE, BFP, and ROU. The factor loadings also indicated sufficient convergent validity of responses to indicator variables (Anderson \& Gerbing, 1988). As already shown in the pilot study, the correlations of both flexibility dimensions with the ROU factor were negative (Penger \& Oswald, 2017). Since, according to our theoretical conceptualization, both BFE and BFP reflect confidence in the ability to overcome mobility-related challenges, the relationship between them was strongly positive. However, a model comparison with a two-factor solution in which all BFE and BFP items load on one common factor did not

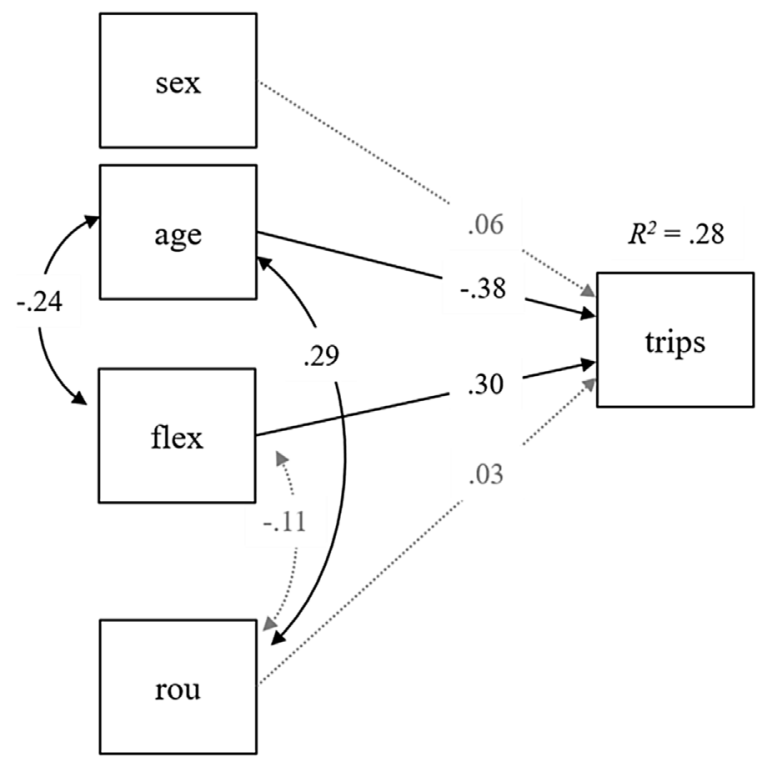

Figure 2. Regression model of flex and rou predicting the number of daily trips in a subsample of mobility-impaired participants $(n=62)$. Standardized estimates for significant coefficients at $p<.05$ are presented. Nonsignificant paths are shown as dotted gray lines. Sex = 0 for female, 1 for male; standardized factor scores were used for the MBFR factors; flex = mobility-related behavioral flexibility consisting of behavioral flexibility concerning environmental challenges (bfe), and concerning personal challenges $(\mathrm{bfp})$; rou = preference for routines and habits; trips = number of daily trips.

describe the data well enough, providing evidence for the three-factorial model. Therefore, we conclude that the MBFR instrument is indeed able to depict BFE and BFP as distinguishable dimensions of mobility-related behavioral flexibility, albeit being highly correlated with one another.

In accordance with our convergent validity assumptions, the results confirmed that participants with high levels of regressive coping $(\mathrm{RC})$ saw themselves as less flexible for environmental (BFE) and personal challenges (BFP) while out and about. Because RC is generally accompanied by feelings of hopelessness, loss of control, and decreased self-regulation (e.g., Staudinger et al., 1998), it contrasts with perceived ability to actively deal with stresses represented by the flexibility dimensions. Hence, negative associations are consistent with the idea that BFE and $\mathrm{BFP}$ reflect person-environment exchange processes of agency characterized by proactive behaviors and a sense of environmental control (e.g., Bandura, 2018; Lawton, 1989; Wahl et al., 2012). As expected, goal-directed and context-specific BFE and BFP were clearly positively related to mobility-related attitudes toward movement in an out-of-home environment. Hence, the findings reinforce the evidence that the MBFR questionnaire captures attitudes toward outdoor mobility in later life rather well. The slightly stronger association of PTC with BFE than with $\mathrm{BFP}$ is consistent with our definition of $\mathrm{BFE}$ as belief in the 
ability to cope with environmental challenges such as different transport modes or trying out new routes. However, the association of OM with BFP was slightly stronger than with BFE. Because BFP reflects perceived ability to adapt mobility-related behavior according to personal challenges, it is likely to combine motivation-oriented behavioral tendencies, e.g., the motivation to go outdoors (Kamin et al., 2016), with the tenacity and self-discipline required to stay mobile in the face of reduced physical or mental health. Thus, these results provide additional support for the distinguishability of the two flexibility dimensions BFE and BFP, as already shown in the factorial validity examination.

It is noteworthy that the association of the third MBFR factor ROU with the specified variables contrasted with the flexibility dimensions. The strongest negative correlation of ROU was with motivation to go outdoors, suggesting that a preference for out-of-home routines was accompanied by the motivational tendency to stay at home. These findings provide new insight into the content-related meaning of this dimension and raise the question of whether ROU directly opposes the flexibility constructs. However, given only the moderate correlation between the flexibility dimensions and ROU, we believe ROU covers further distinct aspects that may be relevant in old age (Penger \& Oswald, 2017). For clarification purposes, further analyses are needed on preferences for routines in the context of outdoor mobility in later life.

We then tested the MBFR instrument in terms of concurrent validity by investigating several hypothesized relationships using structural equation modeling. Concerning assumption 3.1, the results confirmed that participants with a higher FLEX consistently reported more daily trips, providing preliminary evidence of the importance of mobility-related attitudes related to a desire to strive for agency and to stay mobile in old age (cf. Kamin et al., 2016; Penger et al., 2019). However, alternative, more complex measures of outdoor mobility, such as life-space assessments of mobility or modeling mobility on a latent level, may prove to be more strongly associated with FLEX (Baker et al., 2003; Mollenkopf et al., 2005; Stalvey et al., 1999; Webber et al., 2010).

Consistent with assumptions 3.2 and 3.3, individuals with a higher FLEX saw themselves as considerably more independent in activities of daily living (AUT) and showed higher levels of psychological well-being (WELL), reflecting the importance of psychological resources in older adults' quality of life (cf. Bowling et al. 2002; Feltz \& Payment, 2005; Gerino et al., 2017; Tomás et al., 2012). In this context, FLEX may be linked to a proactive adaptation to age-related personal and environmental difficulties, resulting in a better fit between capacity and the demands of the living environment (Lawton 1989; Ryff, 1989;
Slangen-de Kort, 1999; Wahl et al., 2012). Unexpectedly, a preference for routines (ROU) did not predict the number of daily trips in our study. Furthermore, we found no meaningful links between ROU and outcomes of successful aging (AUT and WELL) in the structural model. Considering the small negative bivariate correlation between ROU and TRIPS, the predictive value of ROU may have been limited by the existence of other predicting variables. As highlighted in previous research, in some individuals ROU may be a risk factor for vulnerability (Bergua et al., 2013; Reich \& Zautra, 1991; Zisberg et al., 2009), whereas it functions as an adaptive strategy for others favoring active and successful aging. This may be especially true in older adults with major functional limitations, such as visual, affective, or cognitive impairments (e.g., Bouisson \& Swendsen, 2003; Kaspar et al., 2012; Wahl et al., 2012; Wettstein et al., 2012). Against this background, associations between ROU and outcomes may be curvilinear, with an optimum level of mobility-related routines promoting the maintenance of active and healthy aging and very high and low levels of ROU hindering mobility behaviors or perceived autonomy and well-being (Bitterwolf, 1992). Furthermore, ROU may be causatively rather than correlatively linked to FLEX, with older adults with biographically evolved tendencies toward rigidity behaviors having fewer opportunities to cope with mobility-related challenges in old age. Future longitudinal studies with larger samples would help to clarify these issues. Nevertheless, as already outlined in Penger \& Oswald (2017), a mobility-related preference for routines was considerably more common in older participants. Because ROU is assumed to be associated with aspects of belonging in old age, this finding agrees with previous gerontological research indicating that personenvironment exchange processes (e.g., routines and habits), formed over many years, become more prominent when aging in place (e.g., Bouisson, 2002; Chaudhury \& Oswald, 2019; Oswald \& Konopik, 2015; Oswald et al., 2011; Penger et al. 2019; Rowles \& Bernard, 2013). Thus, ROU may have shown stronger associations when outcomes were linked to urban-related identity in the individual's immediate neighborhood. Overall, this study failed to ascertain whether ROU hinders or fosters outdoor mobility and quality of life. Future research should therefore include processes of belonging, and particularly aspects of place identity and attachment (e.g., Rowles \& Watkins, 2003).

We also investigated the association of MBFR components with actual mobility behavior in a subgroup of participants with mobility-related functional limitations. As anticipated, we found that, especially among older adults at higher risk of reduced mobility, participants with greater FLEX reported nearly twice as many daily outdoor trips as the overall study sample. We therefore conclude that 
mobility-related attitudes play a major role in strengthening or renewing outdoor activity, especially in the mobilityimpaired. Our findings support the view that reduced competencies and increasing environmental demands raise the importance of adaptation processes as expressed by Lawton and Nahemow (1973). Contrary to expectations, ROU again failed to contribute to the prediction of TRIPS. However, because our results give a first impression of the importance of MBFR in vulnerable older adults with lower functional status, these effects should be examined in larger samples that permit testing for moderating effects by applying multigroup analyses, as an investigation of latent factors is likely to reveal greater influence.

\section{Limitations}

Because all study variables were self-reported by participants, errors may have resulted from inaccurate reporting and response bias. Although actual mobility behavior in transport research is often measured in trips per person per day, it is only one of many mobility indicators. Future studies should therefore use combined measures to differentiate travel information by assessing travel time, purpose, and distance (Fillekes et al., 2019).

Because we collected cross-sectional data, interpreting the results is limited in terms of causality. For instance, Haustein (2012) pointed out that the direction of influence of mobility-related attitudes and mobility behavior remains uncertain. Consequently, future longitudinal analyses are highly recommended. Additionally, it should be noted that item reduction and validation of the revised MBFR instrument were carried out on the same data set. Hence, a final cross-validation assessment should be performed.

When conducting structural equation modeling, we used a second-order factor FLEX to represent the commonality of dimensions $\mathrm{BFE}$ and $\mathrm{BFP}$ in light of their high intercorrelation. This procedure seemed reasonable, since both flexibility dimensions showed fairly similar bivariate associations with TRIPS, AUT, and WELL. Nevertheless, this limited the examination of concurrent validity of the MBFR instrument regarding specific predictive effects of $\mathrm{BFE}$ and $\mathrm{BFP}$ on the respective outcome variables.

Finally, the voluntary nature of study participation resulted in reduced control over the sample composition. Participants were of relatively high socioeconomic status and functional capacity, which may have led to an underestimation of effects. Nevertheless, sex distribution was fairly balanced, and age ranged up to 92 years. The generalizability of findings is limited by the inclusion criteria, which restricted participants to community-dwelling older adults living in urban settings and Western societies.

Despite these limitations, the current study uses the MBFR questionnaire to provide a preliminary assessment of the importance of mobility-related behavioral flexibility and routines in old age. To better reflect the complexity of the constructs, we also relied on existing, well-established instruments to measure the impact of latent variables. This procedure may have strengthened the quality of our study.

\section{Implications and Conclusion}

Our results emphasize the importance of mobility-related attitudes in maintaining an independent active life in old age, raise the awareness of psychological resources and the importance of agency processes in the complex dynamics of outdoor movements, and offer new impulses, especially for future research in environmental gerontology, mobility, and health sciences. The concept of MBFR is not only theoretically grounded but can also be operationalized with a reliable and valid self-report questionnaire. From a practical perspective, it would be worthwhile to understand how to influence mobility-related attitudes. Interventions such as exercise and activation programs should perhaps focus on offering older individuals the opportunity to experience personal mastery in the face of mobility-related challenges when out and about, e.g., via neighborhoodbased walking rounds or joint activities with peers. To (re)gain confidence in performing activities of daily living and raising outdoor mobility, such opportunities may be of particular interest when circumstances are demanding, or when sudden changes have occurred, such as relocation, surgery, or a fall. Nevertheless, to enable older adults to actively interact with their living environments, it is important to design stimulating and age-friendly physical infrastructures and make personally meaningful places accessible (Greenfield et al., 2019). Knowledge about psychological determinants of outdoor mobility is crucial to the interdisciplinary discourse of active and healthy aging, e.g., in the fields of transport, urban planning, and in the medical sector, including nursing care and rehabilitation. Ultimately, our work supports the view that older individuals are not only influenced by external conditions but are active agents who interact with and shape their living environments.

\section{References}

Ajzen, I. (1991). The theory of planned behavior. Organizational Behavior and Human Decision Processes, 50(2), 179-211. https://doi.org/10.1016/0749-5978(91)90020-T

Altman, I. (1975). The environment and social behavior: Privacy, personal space, territory, crowding. Brooks/Cole.

Anderson, J. C., \& Gerbing, D. W. (1988). Structural equation modeling in practice: A review and recommended two-step approach. Psychological Bulletin, 103(3), 411-423. https://doi. org/10.1037/0033-2909.103.3.411 
Baker, P. S., Bodner, E. V., \& Allman, R. M. (2003). Measuring lifespace mobility in community-dwelling older adults: LIFE-SPACE MOBILITY. Journal of the American Geriatrics Society, 51(11), 1610-1614. https://doi.org/10.1046/j.1532-5415.2003.51512.x

Bamberg, S., Ajzen, I., \& Schmidt, P. (2003). Choice of travel mode in the theory of planned behavior: The roles of past behavior, habit, and reasoned action. Basic and Applied Social Psychology, 25(3), 175-187. https://doi.org/10.1207/S15324834BASP2503_01

Bandura, A. (1978). Self-efficacy: Toward a unifying theory of behavioral change. Advances in Behaviour Research and Therapy, 1(4), 139-161. https://doi.org/10.1016/0146-6402(78)90002-4

Bandura, A. (2018). Toward a psychology of human agency: Pathways and reflections. Perspectives on Psychological Science, 13(2), 130-136. https://doi.org/10.1177/1745691617699280

Bergua, V., Bouisson, J., Dartigues, J.-F., Swendsen, J., Fabrigoule, C., Pérès, K., \& Barberger-Gateau, P. (2013). Restriction in instrumental activities of daily living in older persons: Association with preferences for routines and psychological vulnerability. The International Journal of Aging and Human Development, 77(4), 309-329. https://doi.org/10.2190/AG.77.4.c

Bergua, V., Fabrigoule, C., Barberger-Gateau, P., Dartigues, J.-F., Swendsen, J., \& Bouisson, J. (2006). Preferences for routines in older people: Associations with cognitive and psychological vulnerability. International Journal of Geriatric Psychiatry, 21(10), 990-998. https://doi.org/10.1002/gps.1597

Bitterwolf, W. (1992). Flexibilität des Handelns: Empirische Untersuchungen zu einem Persönlichkeitskonstrukt [Behavioral flexibility: Empirical studies on a personality construct]. Roderer.

Bollen, K. A. (1980). Issues in the comparative measurement of political democracy. American Sociological Review, 45(3), 370390. https://doi.org/10.2307/2095172

Bouisson, J. (2002). Routinization preferences, anxiety, and depression in an elderly French sample. Journal of Aging Studies, 16(3), 295-302. https://doi.org/10.1016/S0890-4065(02)00051-8

Bouisson, J., \& Swendsen, J. (2003). Routinization and emotional well-being: An experience sampling investigation in an elderly French sample. The Journals of Gerontology Series B: Psychological Sciences and Social Sciences, 58(5), P280-P282. https:// doi.org/10.1093/geronb/58.5.P280

Bowling, A., Banister, D., Sutton, S., Evans, O., \& Windsor, J. (2002). A multidimensional model of the quality of life in older age. Aging \& Mental Health, 6(4), 355-371. https://doi.org/ 10.1080/1360786021000006983

Brandes, H. (1980). Flexibilität und Qualifikation [Flexibility and qualification]. Steinkopff.

Brandtstädter, J., \& Renner, G. (1990). Tenacious goal pursuit and flexible goal adjustment: Explication and age-related analysis of assimilative and accommodative strategies of coping. Psychology and Aging, 5(1), 58-67. https://doi.org/10.1037/08827974.5.1.58

Bundesministerium für Verkehr und digitale Infrastruktur (BMVI). (2018). Mobilität in Deutschland - MiD. Ergebnisbericht [Mobility in Germany - MiD. Result report]. BMVI.

Busch-Geertsema, A., Lanzendorf, M., Müggenburg, H., \& Wilde, M. (2016). Mobilitätsforschung aus nachfrageorientierter Perspektive: Theorien, Erkenntnisse und Dynamiken des Verkehrshandelns [Mobility research from a demand-driven perspective: Theories, insights, and dynamics of transportation behavior]. In O. Schwedes, W. Canzler, \& A. Knie (Eds.), Handbuch Verkehrspolitik (pp. 755-779). Springer Fachmedien. https://doi.org/10.1007/978-3-658-04693-4_33

Carp, F. M. (1988). Significance of mobility for the well-being of the elderly. In Transportation in an aging society: Improving mobility and safety for older persons (Vol. 2, pp. 1-20). Transportation Research Board, National Research Council.
Chaudhury, H., \& Oswald, F. (2019). Advancing understanding of person-environment interaction in later life: One step further. Journal of Aging Studies, 51, Article 100821. https://doi.org/ 10.1016/j.jaging.2019.100821

Conrad, K., Oswald, F., Penger, S., Reyer, M., Schlicht, W., Siedentop, S., \& Wittowsky, D. (2018). Urbane Mobilität und gesundes Altern-Personen- und Umweltmerkmale einer generationsgerechten Stadtgestaltung. Zur Arbeit der Forschungsgruppe autonomMOBIL [Urban mobility and healthy aging - Personal and environmental characteristics of generation-friendly urban design. About the work of the autonomMOBIL research group]. In R. Fehr \& C. Hornberg (Eds.), Stadt der Zukunft - Gesund und nachhaltig (Vol. 1, pp. 291-319). Oekom verlag.

Cumming, R. G., Salkeld, G., Thomas, M., \& Szonyi, G. (2000). Prospective study of the impact of fear of falling on activities of daily living, SF-36 scores, and nursing home admission. The Journals of Gerontology Series A: Biological Sciences and Medical Sciences, 55(5), M299-M305. https://doi.org/ 10.1093/gerona/55.5.M299

Diener, E., Emmons, R. A., Larsen, R. J., \& Griffin, S. (1985). The Satisfaction with Life Scale. Journal of Personality Assessment, 49(1), 71-75. https://doi.org/10.1207/s15327752jpa4901_13

Dunn, T. J., Baguley, T., \& Brunsden, V. (2014). From alpha to omega: A practical solution to the pervasive problem of internal consistency estimation. British Journal of Psychology, 105(3), 399-412. https://doi.org/10.1111/bjop.12046

Engeln, A. (2003). Zur Bedeutung von Aktivität und Mobilität für die Entwicklung im Alter [Activity and mobility and its influence on ageing]. Zeitschrift für Gerontopsychologie \& -Psychiatrie, 16(3), 117-129. https://doi.org/10.1024/1011-6877.16.3.117

Feltz, D. L., \& Payment, C. A. (2005). Self-efficacy beliefs related to movement and mobility. Quest, 57(1), 24-36. https://doi.org/ 10.1080/00336297.2005.10491840

Fillekes, M. P., Kim, E.-K., Trumpf, R., Zijlstra, W., Giannouli, E., \& Weibel, R. (2019). Assessing older adults' daily mobility: A comparison of GPS-derived and self-reported mobility indicators. Sensors, 19(20), Article 4551. https://doi.org/10.3390/ s19204551

Folstein, M. F., Folstein, S. E., \& McHugh, P. R. (1975). Mini-Mental State: A practical method for grading the cognitive state of patients for the clinician. Journal of Psychiatric Research, 12(3), 189-198. https://doi.org/10.1016/0022-3956(75)90026-6

Gellert, P., Ziegelmann, J. P., \& Schwarzer, R. (2012). Affective and health-related outcome expectancies for physical activity in older adults. Psychology \& Health, 27(7), 816-828. https://doi. org/10.1080/08870446.2011.607236

Gellert, P., Witham, M. D., Crombie, I. K., Donnan, P. T., McMurdo, M. E. T., \& Sniehotta, F. F. (2015). The role of perceived barriers and objectively measured physical activity in adults aged 65-100. Age and Ageing, 44(3), 384-390. https://doi.org/ 10.1093/ageing/afv001

Gerino, E., Rollè, L., Sechi, C., \& Brustia, P. (2017). Loneliness, resilience, mental health, and quality of life in old age: $A$ structural equation model. Frontiers in Psychology, 8, Article 2003. https://doi.org/10.3389/fpsyg.2017.02003

Goins, R. T., Jones, J., Schure, M., Rosenberg, D. E., Phelan, E. A., Dodson, S., \& Jones, D. L. (2015). Older adults' perceptions of mobility: A metasynthesis of qualitative studies. The Gerontologist, 55(6), 929-942. https://doi.org/10.1093/geront/ gnu014

Greenfield, E. A., Black, K., Buffel, T., \& Yeh, J. (2019). Community gerontology: A framework for research, policy, and practice on communities and aging. The Gerontologist, 59(5), 803-810. https://doi.org/10.1093/geront/gny089 
Haley, S. M., Jette, A. M., Coster, W. J., Kooyoomjian, J.T., Levenson, S., Heeren, T., \& Ashba, J. (2002). Late life function and disability instrument: II. Development and evaluation of the function component. The Journals of Gerontology Series A: Biological Sciences and Medical Sciences, 57(4), M217-M222. https://doi.org/10.1093/gerona/57.4.M217

Haustein, S. (2012). Mobility behavior of the elderly: an attitudebased segmentation approach for a heterogeneous target group. Transportation, 39(6), 1079-1103. https://doi.org/ 10.1007/s11116-011-9380-7

Hu, L., \& Bentler, P. M. (1999). Cutoff criteria for fit indexes in covariance structure analysis: Conventional criteria versus new alternatives. Structural Equation Modeling: A Multidisciplinary Journal, 6(1), 1-55. https://doi.org/10.1080/10705519909540118

Iwarsson, S., \& Ståhl, A. (2003). Accessibility, usability and universal design: Positioning and definition of concepts describing person-environment relationships. Disability and Rehabilitation, 25(2), 57-66. https://doi.org/10.1080/dre.25.2.57.66

Iwarsson, S., Ståhl, A., \& Löfqvist, C. (2013). Mobility in outdoor environments in old age. In G. D. Rowles \& M. Bernard (Eds.), Environmental gerontology: Making meaningful places in old age (pp. 175-198). Springer-Verlag.

Kamin, S. T., Beyer, A., \& Lang, F. R. (2016). Outdoor motivation moderates the effects of accessibility on mobility in old age. Zeitschrift für Gerontologie und Geriatrie, 49(5), 372-378. https://doi.org/10.1007/s00391-015-0946-4

Karlsruher Institut für Technologie (KIT). (2016). Deutsches Mobilitätspanel (MOP) - Wissenschaftliche Begleitung und Auswertungen Bericht 2015/2016: Alltagsmobilität und Fahrleistung [German Mobility Panel (MOP) - Scientific monitoring and evaluations report 2015/2016: Everyday mobility and mileage]. Bundesministerium für Verkehr und digitale Infrastruktur.

Kaspar, R., Oswald, F., Wahl, H.-W., Voss, E., \& Wettstein, M. (2012). Daily mood and out-of-home mobility in older adults: Does cognitive impairment matter? Journal of Applied Gerontology, 34(1), 26-47. https://doi.org/10.1177/0733464812466290

Lawton, M. P. (1982). Competence, environmental press, and the adaption of older people. In M. P. Lawton, P. G. Windley, \& T. O. Byerts (Eds.), Aging and the environment (pp. 33-59). Springer.

Lawton, M. P. (1989). Environmental proactivity in older people. In V. L. Bengtson \& K. W. Schaie (Eds.), The course of later life (pp. 15-23). Springer

Lawton, M. P., \& Nahemow, L. (1973). Ecology and the aging process. In C. Eisdorfer \& M. P. Lawton (Eds.), The psychology of adult development and aging (pp. 619-674). American Psychological Association.

Lawton, M. P., Moss, M., Hoffman, C., Kleban, M. H., Ruckdeschel, K., \& Winter, L. (2001). Valuation of life: A concept and a scale. Journal of Aging and Health, 13(1), 3-31. https://doi.org/ 10.1177/089826430101300101

McAuley, E., Konopack, J. F., Morris, K. S., Motl, R. W., Hu, L., Doerksen, S. E., \& Rosengren, K. (2006). Physical activity and functional limitations in older women: Influence of selfefficacy. The Journals of Gerontology Series B: Psychological Sciences and Social Sciences, 61(5), P270-P277. https://doi. org/10.1093/geronb/61.5.P270

McDonald, R. P. (1999). Test theory: A unified treatment. Erlbaum.

McDonald, R. P., \& Ho, M.-H. R. (2002). Principles and practice in reporting structural equation analyses. Psychological Methods, 7(1), 64-82. https://doi.org/10.1037/1082-989X.7.1.64

Mollenkopf, H., Marcellini, F., Ruoppila, I., Széman, Z., \& Tacken, M. (Eds.). (2005). Enhancing mobility in later life: Personal coping, environmental resources and technical support; the outof-home mobility of older adults in urban and rural regions of five European countries. IOS Press.
Müggenburg, H., Busch-Geertsema, A., \& Lanzendorf, M. (2015). Mobility biographies: A review of achievements and challenges of the mobility biographies approach and a framework for further research. Journal of Transport Geography, 46, 151-163. https://doi.org/10.1016/j.jtrangeo.2015.06.004

Muthén, L. K., \& Muthén, B. O. (1998). Mplus users' guide (8th ed.). Muthén \& Muthén.

Nordbakke, S., \& Schwanen, T. (2014). Well-being and mobility: A theoretical framework and literature review focusing on older people. Mobilities, 9(1), 104-129. https://doi.org/10.1080/ 17450101.2013 .784542

OECD. (2019). What are equivalent scales? http://www.oecd.org/ els/soc/OECD-Note-EquivalenceScales.pdf

Oswald, F., Jopp, D., Rott, C., \& Wahl, H.-W. (2011). Is aging in place a resource for or risk to life satisfaction? The Gerontologist, 51(2), 238-250. https://doi.org/10.1093/geront/ gnq096

Oswald, F., \& Konopik, N. (2015). Bedeutung von außerhäuslichen Aktivitäten, Nachbarschaft und Stadtteilidentifikation für das Wohlbefinden im Alter [Impact of out-of-home activities, neighborhood and urban-related identity on well-being in old age]. Zeitschrift für Gerontologie und Geriatrie, 48(5), 401-407. https://doi.org/10.1007/s00391-015-0912-1

Oswald, F., \& Wahl, H.-W. (2019). Physical contexts and behavioral aging. In Oxford research encyclopedia of psychology. Oxford University Press. https://doi.org/10.1093/acrefore/ 9780190236557.013 .399

Oswald, F., Wahl, H.-W., \& Kaspar, R. (2005). Psychological aspects of outdoor mobility in later life. In H. Mollenkopf, F. Marcellini, I. Ruoppila, Z. Széman, \& M. Tacken (Eds.), Enhancing mobility in later life: Personal coping, environmental resources, and technical support. The out-of-home mobility of older adults in urban and rural regions of five European countries (pp. 173-194). IOS Press.

Oswald, W. D., Hagen, B., Rupprecht, R., \& Gunzelmann, T. (2002). Bedingungen der Erhaltung und Förderung von Selbstständigkeit im höheren Lebensalter (SIMA) [Maintaining and Supporting Independent Living in Old Age (SIMA)]. Zeitschrift Für Gerontopsychologie \& -Psychiatrie, 15(1), 13-31. https:// doi.org/10.1024/1011-6877.15.1.13

Penger, S., \& Oswald, F. (2017). A new measure of mobility-related behavioral flexibility and routines in old age. GeroPsych, 30(4), 153-163. https://doi.org/10.1024/1662-9647/a000176

Penger, S., Conrad, K., \& Oswald, F. (2018). The role of mobilityrelated behavioral flexibility and routines for out-of-home mobility in an urban setting. Innovation in Aging, 2(Suppl 1), 10-11. https://doi.org/10.1093/geroni/igy023.035

Penger, S., Oswald, F., \& Wahl, H.-W. (2019). Altern im Raum am Beispiel von Wohnen und Mobilität [Ageing in place in the context of housing and mobility]. In K. Hank, F. SchulzNieswandt, M. Wagner, \& S. Zank (Eds.), Alternsforschung. Handbuch für Wissenschaft und Praxis (pp. 413-444). Nomos. https://doi.org/10.5771/9783845276687-413

Perkins, J. M., Multhaup, K. S., Perkins, H. W., \& Barton, C. (2008). Self-efficacy and participation in physical and social activity among older adults in Spain and the United States. The Gerontologist, 48(1), 51-58. https://doi.org/10.1093/geront/ 48.1.51

Phillips, J., Walford, N., Hockey, A., Foreman, N., \& Lewis, M. (2013). Older people and outdoor environments: Pedestrian anxieties and barriers in the use of familiar and unfamiliar spaces. Geoforum, 47, 113-124. https://doi.org/10.1016/ j.geoforum.2013.04.002

Rantakokko, M., Mänty, M., Iwarsson, S., Törmäkangas, T., Leinonen, R., Heikkinen, E., \& Rantanen, T. (2009). Fear of moving outdoors and development of outdoor walking difficulty in older people: Fear of moving outdoors and walking 
difficulties. Journal of the American Geriatrics Society, 57(4), 634-640. https://doi.org/10.1111/j.1532-5415.2009.02180.x

Rantanen, T. (2013). Promoting mobility in older people. Journal of Preventive Medicine \& Public Health, 46(Suppl 1), S50-S54. https://doi.org/10.3961/jpmph.2013.46.S.S50

Reich, J.W., \& Zautra, A.J. (1991). Analyzing the trait of routinization in older adults. The International Journal of Aging and Human Development, 32(3), 161-180. https://doi.org/ 10.2190/4PKR-F87M-UXEQ-R5J2

Rosenberg, M. J., \& Hovland, C. I. (1960). Cognitive, affective and behavioral components of attitudes. In C. I. Hovland \& M. J. Rosenberg (Eds.), Attitude, organization and change: An analysis of consistency among attitude components (pp. 1-14). Yale University Press.

Rowles, G. D. \& Bernard, M. (Eds.). (2013). Environmental gerontology: Making meaningful places in old age. Springer-Verlag.

Rowles, G. D., \& Watkins, J. F. (2003). History, habit, heart and hearth: On making spaces into places. In K. W. Schaie, H.-W. Wahl, H. Mollenkopf, \& F. Oswald (Eds.), Aging independently: Living arrangements and mobility (pp. 77-96). Springer-Verlag.

Ryff, C. D. (1989). Happiness is everything, or is it? Explorations on the meaning of psychological well-being. Journal of Personality and Social Psychology, 57(6), 1069-1081. https://doi.org/ 10.1037/0022-3514.57.6.1069

Satorra, A., \& Bentler, P. M. (2001). A scaled difference chi-square test statistic for moment structure analysis. Psychometrika, 66 (4), 507-514. https://doi.org/10.1007/BF02296192

Scheiner, J. (2006). Does the car make elderly people happy and mobile? Settlement structures, car availability and leisure mobility of the elderly. European Journal of Transport and Infrastructure Research, 6(2). https://doi.org/10.18757/ EJTIR.2006.6.2.3431

Schermelleh-Engel, K., Moosbrugger, H., \& Müller, H. (2003). Evaluating the fit of structural equation models: Tests of significance and descriptive goodness-of-fit measures. Methods of Psychological Research, 8(2), 23-74.

Siltanen, S., Rantanen, T., Portegijs, E., Tourunen, A., PoranenClark, T., Eronen, J., \& Saajanaho, M. (2019). Association of tenacious goal pursuit and flexible goal adjustment with outof-home mobility among community-dwelling older people. Aging Clinical and Experimental Research, 31(9), 1249-1256. https://doi.org/10.1007/s40520-018-1074-y

Skantz, H., Rantanen, T., Palmberg, L., Rantalainen, T., Aartolahti, E., Portegijs, E., Viljanen, A., Eronen, J., \& Rantakokko, M. (2020). Outdoor mobility and use of adaptive or maladaptive walking modifications among older people. The Journals of Gerontology: Series A, 75(4), 806-812. https://doi.org/10.1093/gerona/glz172

Skinner, E. A. (1996). A guide to constructs of control. Journal of Personality and Social Psychology, 71(3), 549-570. https://doi. org/10.1037/0022-3514.71.3.549

Slangen-de Kort, Y. A. W. (1999). A tale of two adaptations: Coping processes of older persons in the domain of independent living. Eindhoven University of Technology. https://doi.org/10.6100/ IR519930

Slaug, B., Jonsson, O., \& Carlsson, G. (2019). Public entrance accessibility: Psychometric approach to the development of a new assessment instrument. Disability and Health Journal, 12(3), 473-480. https://doi.org/10.1016/j.dhjo.2019.02.007

Sniehotta, F. F., Gellert, P., Witham, M. D., Donnan, P. T., Crombie, I. K., \& McMurdo, M. E. (2013). Psychological theory in an interdisciplinary context: Psychological, demographic, healthrelated, social, and environmental correlates of physical activity in a representative cohort of community-dwelling older adults.
International Journal of Behavioral Nutrition and Physical Activity, 10(1), Article 106. https://doi.org/10.1186/1479-5868-10-106

Stalvey, B. T., Owsley, C., Sloane, M. E., \& Ball, K. (1999). The Life Space Questionnaire: A measure of the extent of mobility of older adults. Journal of Applied Gerontology, 18(4), 460-478. https://doi.org/10.1177/073346489901800404

Staudinger, U. M., Freund, A. M., Linden, M., \& Maas, I. (1998). Self, personality, and life regulation: Facets of psychological resilience in old age. In P. B. Baltes \& K. U. Mayer (Eds.), The Berlin aging study (pp. 302-328). Cambridge University Press. https://doi.org/10.1017/CB09780511586545.012

Tinetti, M. E., De Leon, C. F. M., Doucette, J. T., \& Baker, D. I. (1994). Fear of falling and fall-related efficacy in relationship to functioning among community-living elders. Journal of Gerontology, 49(3), M140-M147. https://doi.org/10.1093/geronj/49.3.M140

Tomás, J. M., Sancho, P., Melendez, J. C., \& Mayordomo, T. (2012). Resilience and coping as predictors of general well-being in the elderly: A structural equation modeling approach. Aging \& Mental Health, 16(3), 317-326. https://doi.org/10.1080/ 13607863.2011.615737

Wahl, H.-W., Iwarsson, S., \& Oswald, F. (2012). Aging well and the environment: Toward an integrative model and research agenda for the future. The Gerontologist, 52(3), 306-316. https://doi.org/10.1093/geront/gnr154

Ware, J. E., Kosinski, M., \& Keller, S. D. (1996). A 12-Item ShortForm Health Survey: Construction of scales and preliminary tests of reliability and validity. Medical Care, 34(3), 220-233.

Watson, D., Clark, L. A., \& Tellegen, A. (1988). Development and validation of brief measures of positive and negative affect: The PANAS scales. Journal of Personality and Social Psychology, 54(6), 1063-1070. https://doi.org/10.1037/00223514.54.6.1063

Webber, S. C., Porter, M. M., \& Menec, V. H. (2010). Mobility in older adults: A comprehensive framework. The Gerontologist, 50(4), 443-450. https://doi.org/10.1093/geront/gnq013

Wettstein, M., Wahl, H.-W., Shoval, N., Oswald, F., Voss, E., Seidl, U., Frölich, L., Auslander, G., Heinik, J., \& Landau, R. (2012). Outof-home behavior and cognitive impairment in older adults: Findings of the SenTra Project. Journal of Applied Gerontology, 34(1), 3-25. https://doi.org/10.1177/0733464812459373

Wood, W., Tam, L., \& Witt, M. G. (2005). Changing circumstances, disrupting habits. Journal of Personality and Social Psychology, 88(6), 918-933. https://doi.org/10.1037/00223514.88.6.918

Yesavage, J. A., Brink, T. L., Rose, T. L., Lum, O., Huang, V., Adey, M., \& Leirer, V. O. (1983). Development and validation of a Geriatric Depression Screening Scale: A preliminary report. Journal of Psychiatric Research, 17(1), 37-49. https://doi.org/ 10.1016/0022-3956(82)90033-4

Zisberg, A., Zysberg, L., Young, H. M., \& Schepp, K. G. (2009). Trait routinization, functional and cognitive status in older adults. The International Journal of Aging and Human Development, 69(1), 17-29. https://doi.org/10.2190/AG.69.1.b

\section{History}

Received December 3, 2020

Accepted April 30, 2021

Published online June 10, 2021

\section{Acknowledgments}

The authors are grateful to Phillip Elliott for comprehensively editing the manuscript. We also thank the participants who made this study possible. 


\section{Conflict of interest}

The authors declare no conflict of interest.

\section{Author Note}

Susanne Penger is now at the Department of Psychological Ageing Research (PAR), Institute of Psychology, University of Siegen, Germany.

\section{Editorial Note}

The acting editor was Frieder R. Lang.

\section{Funding}

The present work is part of the project amore funded by the Dr. PRITZSCHE Foundation, Germany. The empirical study MBIS was conducted as part of the Research Group autonomMOBIL supported by the Fritz und Hildegard Berg-Foundation, Germany.
Open access publication enabled by University Library Johann Christian Senckenberg.

\section{ORCID}

Susanne Penger

(iD) https://doi.org/0000-0003-3417-6154

\section{Susanne Penger}

Interdisciplinary Ageing Research (IAW)

Faculty of Educational Sciences

Campus Westend

PEG Building

Theodor-W.-Adorno-Platz 6

60323 Frankfurt am Main

Germany

penger@em.uni-frankfurt.de 